\title{
СТРАТЕГИЯ ПРОСТРАНСТВЕННОГО РАЗВИТИЯ: РЕАЛИЗУЕМ ЛИ ПЛАН РЕАЛИЗАЦИИ?
}

\author{
(c) 2020 Валентик Ольга Николаевна \\ научный сотрудник \\ Институт экономики Российской академии наук, Россия, Москва
}

Принятие плана действий по реализации Стратегии пространственного развития Российской Федерации во многом сняло опасения того, что Стратегия как документ стратегического планирования вообще будет признана нежизнеспособной и будет или заменена, или целиком интегрирована в «базовую» Стратегию социально-экономического развития Российской Федерации, которую теперь предстоит утвердить на период до 2050 года. Однако содержание «плана реализации» не убеждает в том, что с принятием данного документа осуществление Стратегии приобрело достаточные черты конкретности и достоверности.

Ключевые слова: стратегическое планирование, пространственное развитие, институты регулирования, экономическое обеспечение.

Ход работы над Стратегией пространственного развития Российской Федерации до 2025 года (СПР) [5] отразил в себе все слабые стороны российской практики стратегического планирования. Период этой работы затянулся (Стратегия «опоздала» не менее, чем на 2 года по сравнению с первоначальными ориентирами). Проекты этого документа многократно обсуждались на различных форумах, «круглых столах» и пр., но в итоге был утвержден тот его вариант, который не подвергался серьезной экспертизе. Характерна следующая последовательность событий: 6 февраля 2019 г. Совет Безопасности РФ высказывает критические замечания в адрес Правительства РФ и Минэкономразвития РФ за срыв работы по подготовке ключевых документов стратегического планирования [7], а уже через неделю - 13 февраля 2019 г. как ответ принимается Стратегия пространственного развития.

Есть и еще ряд признаков, характеризующих СПР как типичный продукт российской практики стратегирования. Прежде всего, следует обратить внимание, что при подготовке СПР не удалось реализовать все те установочные положения, которые предварительно были сформулированы в ряде нормативно-правовых документов. В частности, это - Постановление Правительства РФ № 870, принятое в 2015 г. [3]. В результате сложилась ситуация, когда не СПР строилась согласно положениям данного Постановления, а само постановление «пост-фактум» корректировалось по то, что фактически удалось отразить в СПР. После корректировки 870-го Постановления из него «исчезли» такие важные установки в отношении СПР, как отражение в ней изменений структуры экономики Российской Федерации в региональном аспекте; отражение перспективных конкурентных преимуществ и экономической специализации субъектов Федерации в межрегиональном разделении труда в соответствии с их типологической принадлежностью. «Утерянной» оказалась также установка на обеспечение согласованности приоритетов отраслевого и регионального развития; на отражение вариантов территориального размещения национальных технологических платформ и многое другое.

В равной мере обращает на себя внимание такая особенность СПР, как невнимание к целевой функции и механизмам реализации представленных в ней институциональных новаций. Это такие новации, как выделение группы геостратегических субъектов Федерации [1]; перспективные специализации российских регионов; перспективные «точки» экономического роста, ранжированные по их потенциальному вкладу в ВВП страны и пр. Кроме того, о реализации того или иного программно-стратегического документа принято судить по выполнению его количественных индикаторов (целевых показателей). В этом смысле действующий вариант СПР вызывает удивление: при большом разнообразии различных принципиальных установок по вопросам пространственного развития российской экономики, в итоге в СПР включено лишь 5 целевых показателей, отражающих при этом да- 
леко не самые важные стороны этого документа.

Нельзя пройти и мимо того факта, что ни сама СПР, ни план ее реализации не содержат показателей, характеризующих экономическую «стоимость» реализации данной стратегии, т.е. указания на те объемы финансовых (прежде всего, бюджетных) ресурсов, которые потребуются на практическое осуществление основных положений этого документа на всем протяжении его действия. Согласование стратегического и бюджетного планирования выступает одной из важнейших предпосылок успешности стратегирования как качественно более высокого уровня государственного и муниципального. Однако такое согласование возможно только при условии, что документы стратегического планирования будут содержать в себе не только изложение общих намерений, но и количественную оценку намечаемых расходов, причем сообразно каждому уровню бюджетной системы. Если в той или иной Стратегии и/или в плане по ее реализации нет ни одной цифры по бюджетным расходам, необходимым для ее реализации, то о каком согласовании может идти речь? Подобное согласование возможно только в том случае, если планы реализации этих стратегических документов (как в случае со СПР) будут изложены не в виде перечня «докладов» и «актов», «распоряжений» и пр., а через систему экономически обсчитанных государственных программ и/или национальных проектов.

На фоне этих и иных обстоятельств было довольно трудно ожидать, что план реализации СПР [6] составит собой достаточно конкретную и разносторонне обеспеченную программу в регулировании пространственных параметров российской экономики. План состоит из нескольких разделов, а именно: 1. Мероприятия, способствующие достижению национальных целей и стратегических задач развития Российской Федерации; 2. Сокращение уровня межрегиональной дифференциации в социальноэкономическом развитии субъектов Федерации; 3. Социально-экономическое развитие геостратегических территорий Российской Федерации; 4. Обеспечение расширения географии и ускорения экономического роста. Всего план включает в себя 100 позиций, которых 58 - доклады Правительству РФ. В этом смысле документ явно не смотрится как программа конкретных действий по реализации актуальных задач регулирования пространственной структуры экономики.
Нельзя не согласиться тем, что предметом многих докладов выступают значимые проблемы регулирования пространственной структуры российской экономики. Но доклад - это только доклад, т.е. документ, находящийся на «дальних подступах» к практическому решению тех или иных проблем. Между тем, срок действия СПР невелик и, как полагают многие эксперты, не вполне соразмерен масштабности поставленных в ней задач. Из числа позиций плана реализации 21 позиция - это подготовка различных нормативно-правовых актов Правительства РФ и 15 позиций - подготовка ведомственных актов. 5 позиций предполагают разработку проектов федеральных законов и 1 позиция - подготовку «иных актов».

В блоке законодательных инициатив, которые обозначены в плане реализации, есть ряд значимых позиций. В частности, это внесение в Федеральный закон «О промышленной политике в Российской Федерации» изменений о наделении органов государственной власти субъектов Федерации полномочиями в области деятельности институтов промышленного развития, создания и функционирования межотраслевых кластеров, в т.ч. с учетом перспективных экономических специализаций регионов. Сюда же следует отнести и разработку проекта федерального закона о городских агломерациях.

Сопоставление плана реализации с самой Стратегией - показывает, что план так или иначе «покрывает» одни позиции Стратегии, но оставляет без внимания некоторые другие. Например, существенное место в Стратегии занимает идентификация так называемых перспективных центров экономического роста, ранжированных по их потенциальному вкладу в ВВП страны и, в ряде случае, по профилю экономической деятельности (минерально-сырьевые центры, агропромышленные центры, научнообразовательные центры мирового уровня и пр.). Стратегия специально обращает внимание на недостаточное количество центров экономического роста для обеспечения ускорения экономического роста Российской Федерации, хотя и не дает оснований полагать, какое именно количество таких центров будет достаточным для устойчивого социально-экономического развития страны.

Однако в плане реализации не представлено системного комплекса мер, способных подвигнуть названные в СПР перспективные центры 
роста на тот вклад в социально-экономическое развитие страны, который предзадан им в этом документе. В результате складывается ситуация, когда вопрос о том, кому и зачем адресуется этот обширный перечень «перспективных центров роста» остается без ответа. В отсутствие финансово-бюджетных обоснований остается без ответа и вопрос о том, какое число «перспективных центров роста» в период действия Стратегии реально сможет получить поддержку от государства в экономически значимых масштабах.

Ни один из блоков плана реализации не содержит характерных для него целевых индикаторов. Как уже отмечалось, Стратегия пространственного развития содержит пять ее целевых индикаторов. Поскольку план реализации никаких собственных целевых показателей не содержит, есть все основания считать, что целевые показатели Стратегии могут одновременно считаться и целевыми показателями плана реализации. Но и эти показатели вызывают определенные сомнения в их значимости как индикаторов значимых сдвигов в пространственной структуре российской экономики. Например, это относится к такому индикатору, как «среднегодовые темпы роста ВРП субъектов Российской Федерации, в которых располагаются перспективные крупные центры экономического роста». Смысл этого индикатора, видимо, состоит в том, что темпы роста ВРП данной группы субъектов Федерации должны быть выше среднероссийских. Однако даваемые здесь числовые значения - 102,6\% или 103,7\% к 2025 г. (инерционный и целевой сценарии) практически не отличаются от прогнозных величин для экономики страны в целом [4].

В наибольшей мере проблема отсутствия четкого целеполагания касается такого блока плана реализации, как «Сокращение уровня межрегиональной дифференциации в социальноэкономическом развитии субъектов Российской Федерации». Следует напомнить, что предварительные варианты (проекты) СПР, в отличие от е итогового варианта, содержали некоторые оценки сдвигов в отношении данной дифференциации. Именно поэтому, на наш взгляд, именно этот блок плана реализации особенно «взывает» к той самой «оценке регулирующего воздействия», которая в последнее время активно используется при разработке и экспертизе различных нормативно-правовых актов и отдельных решений органов исполнительной власти.

Между тем, в целевых индикаторах Стратегии этому блоку вопросов соответствует такой показатель как межрегиональная дифференциация индекса человеческого развития. В соответствии со Стратегией, этот показатель к 2025 г. по целевому сценарию должен сократиться на 3\%, а по инерционному варианту - увеличиться на $1 \%$. Крайне трудно согласиться с тем, что такой статистически узко нацеленный показатель как индекс человеческого развития [2], да еще при его изменении в столь незначительных границах, может выступать более-менее достоверным индикатором сдвигов в экономической дифференциации регионов России. Кроме того, остается неясным и то, какой метод оценки межрегиональной дифференциации в данном случае имеется в виду (по «крайним» точкам, с использованием так наз. «децильных коэффициентов» и пр.).

Из плана реализации остается неясным и тот механизм, через действие которого предполагается осуществить позитивные изменения в экономической дифференциации регионов. В соответствующий блок плана реализации включены следующие разделы: конкурентоспособная экономика субъектов Российской Федерации (перспективные экономические специализации); совершенствование территориальной организации оказания услуг отраслей социальной сферы; социально-экономическое развитие городских территорий; социально-экономическое развитие сельских территорий. Все это вопросы, безусловно, очень значимые для хозяйственного и социального развития страны. Однако прямой нацеленности на сокращение параметров межрегиональной экономической дифференциации они не имеют. В этой связи нельзя однозначно утверждать, что предусмотренные здесь мероприятия будут действовать именно в сторону сокращения межрегиональной экономической дифференциации, а не в сторону ее усиления.

Очень важный вопрос касается того, какие именно механизмы предлагаются планом для реализации целевых установок Стратегии пространственного развития. Так, например, Стратегия констатирует наличие такой проблемы, как «нереализованный потенциал межрегионального и межмуниципального взаимодействия». Однако в плане не предусмотрено конкретных мер, направленных на активизацию 
практики межрегионального взаимодействия (например, с использованием возможностей межрегиональных ассоциаций экономического взаимодействия).

Не менее важно обратить внимание на то, что план реализации в целом характеризуется слабой координацией с программно-целевыми методами управления, которые в соответствии с законом о стратегическом планировании [8] являются основным рычагом осуществления целей и задач, формируемых в практике стратегического планирования. В действующей системе государственных программ Стратегии корреспондирует блок «Сбалансированное региональное развитие». Однако заметно, что план реализации Стратегии никак не опирается на данную блок государственных программ и не предусматривает ее корректировку под обозначенные в СПР приоритеты. «Программный аппарат» плана реализации выглядит скудно. Помимо общих установок на совершенствование программно-целевых методов управления в соответствии с приоритетами СПР, план реализации не содержит значимых программных инициатив. Исключение выступает разработка подпрограммы «Развитие моногородов» госу- дарственной программы Российской Федерации «Экономическое развитие и инновационная экономика» (предусмотренная в СПР программа «Комплексное развитие сельских территорий» утверждена Постановлением Правительства РФ от 31 мая 2019 г. № 696).

Еще один важный момент. В СПР есть запись о том, что документ направлен на обеспечение скоординированных действий федеральных органов исполнительной власти, органов государственной власти субъектов Федерации, органов местного самоуправления по реализации приоритетов пространственного развития. Однако на деле в плане реализации акцент делается на инициативы и действия федерального центра; роль субфедерального звена представлена достаточно пассивно, в частности, в плане становления пространственного стратегирования на региональном уровне. В результате, в плане нет указаний на пути решения такой поставленной в СПР проблемы, как преодоление существенных внутрирегиональных различия по уровню социально-экономического развития. Скорее всего, обновление СПР приведет и к существенным корректировкам в плане реализации этого документа стратегического планирования.

\section{Библиографический список}

1. Валентик О.Н. Геостратегические территории как инструмент политики пространственного регулирования в экономике // Экономические науки. 2019. июнь. (№ 175). С. 30-33.

2. Матушкина Ю.Н. Сравнительный анализ регионов России по индексу человеческого развития // Экономика и управление: проблемы, решения. 2017. № 5. С. 44-49.

3. Постановление Правительства РФ от 20 августа 2015 г. № 870 «О содержании, составе, порядке разработки и утверждения стратегии пространственного развития Российской Федерации, а также о порядке осуществления мониторинга и контроля ее реализации». [Электронный ресурс] URL: http://base.garant.ru/ 71170676.

4. Прогноз социально-экономического развития Российской Федерации на период до 2036 года (разработан Минэкономразвития России). [Электронный ресурс] URL: https://legalacts.ru/doc/prognoz-sotsialnoekonomicheskogo-razvitija-rossiiskoi-federatsii-na-period-do-2036/

5. Распоряжение Правительства РФ от 13 февраля 2019 г. № 207-р «Об утверждении Стратегии пространственного развития Российской Федерации на период до 2025 года». [Электронный ресурc] URL: http://www. consultant.ru/document/cons_doc_LAW_25312/.

6. Распоряжение Правительства РФ от 27 декабря 2019 г. № 3227-р «Об утверждении плана реализации Стратегии пространственного развития Российской Федерации на период до 2025 года». [Электронный ресурс] URL: http://www.consulnant.ru/document/cons_doc_LAW_34252/.

7. Секретарь Совета Безопасности РФ Николай Патрушев провел совещание по вопросам стратегического планирования. [Электронный ресурс] URL: http://www.scrf.gov.ru/news/allnews/2538/.

8. Федеральный закон от 28 июня 2014 г. № 172-ФЗ «О стратегическом планировании в Российской Федерации». [Электронный ресурс] URL: http://www.consultant.ru/document/cons_doc_LAW_164841/. 